\title{
Por uma história social das mulheres: os movimentos sufragistas uruguaios
}

El Sufrágio.

VASQUES, Maria L. Osta.

Montevidéu: Obsur, 2006. 155 p.

Há aproximadamente vinte anos iniciavam-se os trabalhos do Observatório do Sul (OBSUR), que tinham como pretensão investigar as atividades desenvolvidas pelas mulheres uruguaias. Nas mais diversas áreas das Ciências Humanas, mais do que temáticas e objetos de pesquisa, O OBSUR buscava inclusive transformar as próprias pesquisadoras em sua trajetória investigativa. Tratava-se, portanto, de um duplo trabalho em que objeto e pesquisadora eram os alvos e do qual o presente livro de Maria Laura Osta é tributário ao se apresentar como o primeiro número da série de Cadernos do OBSUR.

Calcada em uma perspectiva de História Social, essa obra, ainda que se diferencie da literatura de gênero, tem como principal pretensão enxergar as mulheres uruguaias como sujeitos ativos com importante participação no avanço das conquistas políticas durante fins do século XIX e início do XX. Essas mulheres modificaram os papéis sociais femininos e imprimiram importantes transformações no seio da sociedade uruguaia, como a conquista do voto em 1932.

Mesmo diante de uma grande dificuldade no acesso a documentos relativos ao processo sufragista, expressa na falta de informação das instituições e no próprio desgaste físico das evidências, a autora lançou mão de uma larga variedade de fontes. Para a pesquisa, utilizou teses realizadas pelos alunos de Direito acerca da participação das mulheres no âmbito político, projetos apresentados no Parlamento, obras do bispo Mariano Soler, além de jornais como El Democrata que mostravam as formas de relação entre Igreja e sociedade.

Trata-se, portanto, de uma história social das mulheres uruguaias, isto é, uma análise em que a compreensão das grandes estruturas dá lugar a uma pesquisa que busca não resgatar um passado único, mas uma história do trabalho, das mulheres, da sexualidade, entre tantas outras, como havia afirmado Robert Darnton. ${ }^{1}$

Dessa forma, temos uma história que deixa de analisar o político na perspectiva positivista, isto é, como espaço de atuação dos homens imersos nos grandes feitos e nos fatos marcantes. O convite feito por Maria Laura Osta é para 
compreendermos o sujeito em suas várias formas e níveis de participação. É para percebermos, por exemplo, a ação das mulheres no nível cotidiano avançando em suas conquistas políticas. Amplia-se, portanto, a percepção de suas ações em espaços de atuações tidos, até bem pouco tempo, como exclusivamente masculinos.

O livro, dividido em cinco partes, inicia-se com o capítulo intitulado de "Los movimientos feministas mundiales por el sufrágio". Nesse momento, a autora demonstra como havia no Uruguai uma circularidade de ideias e questões de caráter mundial referentes às lutas feministas. Isso fica expresso, por exemplo, na presença da espanhola Belén de Sórroga, que serve para ilustrar uma das formas como as uruguaias tinham conhecimento dos debates feministas em escala mundial. Assim, partindo da ideia contraditória de igualdade jurídica, inaugurada pelas revoluções modernas, a autora mapeia os diferentes avanços dos feminismos em escala nacional e internacional. Contudo, é possível observar alguns problemas nessa forma de abordagem que ocultam um pouco a profundidade, relevância e importância do restante da obra. O feminismo, ou melhor, a sua história, aparece de forma engessada em uma perspectiva linear e evolucionista, além de não haver uma crítica aprofundada das fontes. Os jornais, por exemplo, não são problematizados quanto ao seu alcance e ao público leitor, entre outros aspectos.

Entretanto, no segundo capítulo, "La condición femenina: de lo privado a lo público", ao se preocupar em analisar "A geração dos 1900", a autora adentra mais cuidadosamente as fontes. Através de teses de Direito, demonstra que era latente a discussão sobre o sufrágio feminino nos debates jurídicos, pois para alguns esse direito era natural, enquanto para outros a mulher perderia seu encanto delicado, e resultaria na destruição da família. Dessa forma, a autora retrata uma nova mentalidade na virada do século XIX para o XX, mostrando uma mulher que expressava sua opinião e ascendia pública e politicamente em uma sociedade patriarcal.

Uma aceitação que não ocorria, também, era no mundo do trabalho, em que Osta constata que as mulheres eram a maioria, gerando uma concorrência que despertava a revolta dos homens. Porém, aos poucos conquistaram algumas leis, como a da silla, ${ }^{2}$ em 1918. Maria L. Osta aponta que essas leis previam os cuidados devido à mulher ser mais fraca e inferior ao homem, mas ao mesmo tempo garantiam a entrada e a permanência delas no mundo do trabalho. No tocante à educação feminina, esta se torna mais acessível para a leitura e escrita, a partir de 1795, quando a mulher passa a ser vista como a educadora dos futuros cidadãos. Mas é no exercício da docência que, segundo a autora, as mulheres ganham notoriedade, pois essa profissão lhes é legada devido aos baixos salários, que para os homens seriam insuficientes. Conforme estudos de historiadores, a autora afirma que essa foi a abertura para o ensino primário feminino, e principalmente o caminho para a igualdade política, junto à criação da Escola Normal, em 1882, e à permissão para estudos universitários, em 1879.

No terceiro capítulo, "Conquistas políticas de la mujer em Uruguay", cujo propósito é demonstrar a ação e o protagonismo das mulheres uruguaias ao longo da história do país, Maria Laura Osta contrasta inicialmente a imagem passiva que se pretendia da mulher no século XIX com os primeiros movimentos do início do século XX que abordavam o tema da "questão feminina" e eram expressos nos êxitos dos projetos de leis que contemplavam os direitos civis e políticos das mulheres.

Nesse bojo nem sempre as ações das mulheres eram convergentes. Isso ficava evidente, por exemplo, nas diferenças de interesses entre as sufragistas e as trabalhadoras. As primeiras inclinavam-se ao avanço das conquistas no campo político, enquanto as segundas focavam as conquistas de caráter material, social e econômico.

De fato, como nos lembra Ângela de Castro Gomes, os logros em um determinado âmbito podem não vir acompanhados de sucessos nos outros. ${ }^{3}$ Direitos políticos, civis e sociais não, necessariamente, estão articulados, como se pode observar na história do Brasil. Contudo, no Uruguai, uma militante sufragista, Paulina Luisi, acreditava que a conquista do direito ao sufrágio seria seguida por consideráveis avanços de caráter social. Ela era uma das mais altas expressões do protagonismo e da consciência das mulheres, que, segundo Laura Osta, paulatinamente, conquistavam espaços públicos e políticos através de reuniões, conferências, publicações, empregos, gestões de instituições públicas, entre outros modos de participação.

Entretanto, muitas vezes esses progressos eram seguidos de recuos e perdas, o que a autora atribui de forma perspicaz à manutenção de uma ideologia dominante patriarcalista, aceita por muitas militantes que, ao defenderem a criação de um partido feminista, viam a mulher a partir de uma perspectiva sexista, isto é, como 
algo complementar ao homem, ligada ao sentimento que auxiliaria a razão masculina. Enfim, aspectos paradoxais e bem observados de um feminismo de primeira onda que limitavam ou eram limitados pelas diretrizes do partido. ${ }^{4}$

No seu penúltimo capítulo a autora escrutina também as diferentes posições assumidas dentro da lgreja Católica quanto à participação da mulher no âmbito político. São três as principais vias de atuação: o jornal EI Democrata e o El Bien Público e as ações tomadas pelo bispo Mariano Soler, que, de acordo com o contexto histórico, poderiam assumir nuanças de apoio ou rechaço aos direitos das mulheres. Esses aspectos, quando apresentados pela historiografia uruguaia tradicional, tendiam a ocultar a importância da participação das mulheres, mas, quando abordados por Maria Laura Osta, apontam a heterogeneidade existente dentro da própria Igreja e permitem, inclusive, sinalizar um quarto aspecto: a importância da organização das mulheres católicas na busca de seus direitos, mesmo com conotações de caráter conservador.

Ainda nesse capítulo, a autora aponta $e$ discute a heterogeneidade presente dentro do batllismo e do liberalismo. Assim, em uma espécie de tripé (catolicismo, batllismo e liberalismo) se evidenciariam os paradoxos e as facetas plurais assumidas em torno da "questão feminina", ora apresentando aproximações, ora indicando distanciamentos e disputas, tal como o estreitamento entre o batllismo e o "feminismo da compensação", posturas que, quando tomadas em conjunto, visualizariam a mulher como 0 futuro da sociedade, embora com objetivos e ênfases diferenciadas. Havia assim uma pluralidade de ideologias no Uruguai na primeira metade do século XX que, por diversas vezes, esbarravam nas condições materiais e nas ações das mulheres, protagonistas de suas próprias histórias.

Quanto à última parte do livro, a autora discute os oito projetos de lei acerca da defesa do sufrágio feminino no Uruguai que se iniciaram em 1914 e culminaram com a aprovação do direito ao voto em 1932. Sob a influência das teses de John Stuart Mill, a importância desses debates estava respaldada no argumento da busca de uma sociedade mais igualitária que deveria garantir a defesa das mulheres e os seus acessos a cargos públicos, possibilitando, assim, a substituição das práticas consuetudinárias pela ascensão de direitos constitucionais. Trava-se, principalmente, do combate aos argumentos que apontavam a mulher como um ser inferior nos aspectos mental e biológico.

De amplo alcance, o projeto de lei previa uma intensa revisão da Constituição de 1830 , texto em as mulheres nem sequer eram vistas como cidadãs. No intenso debate legislativo, Laura Osta destaca, por um lado, a participação das Ligas e Associações feministas que lutavam para desfazer aquela ideia de inferioridade intelectual das mulheres, mas, por outro, a ausência dos anarquistas além da aversão do Partido Católico que ratificava os papéis sociais conservadores ligados ao sexo feminino.

No avanço das discussões, observa-se, pouco a pouco, a confluência dos partidos em aceitar a participação das mulheres na políica. Contudo, como bem observa a autora, isso ocorria de maneira contraditória. Ainda que essa participação no âmbito público tenha ocorrido em virtude da ação e luta das mulheres que buscavam igualdade entre os sexos, os homens achavam que a participação delas no âmbito político era necessária porque, enquanto mulheres, teriam maior sensibilidade para tratar de certos assuntos e temáticas. Permanecia a ideia de inferioridade feminina, ainda que as mulheres fossem direcionadas para novas funções sociais. O êxito da análise de Maria Laura Osta está em mostrar que, mesmo permeadas por noções conservadoras e patriarcalistas, as posições do Partido Batlista e da Igreja Católica, paulatinamente, facilitaram as discussões e as primeiras conquistas civis das mulheres.

Entrementes, esse livro, longe de representar uma história linear na qual as mulheres tiveram seus anseios no mundo político atendidos, aponta para a necessidade de se perpetuar uma organização engajada em verificar uma realidade em que ainda há muito por se fazer e modificar. Divididas entre as tarefas domésticas não remuneradas e as atividades extralar, as mulheres uruguaias representam apenas $12 \%$ da participação no governo, mesmo sendo o voto feminino uma conquista naquele espaço há quase 80 anos. Assim, o livro de Maria Laura Osta nos instiga a pensar o quanto foi feito $e$, sobretudo, o tanto que se pode e deve fazer na busca por dirimir as desigualdades com base na diferença sexual, sejam elas no âmbito social, político e econômico.

\section{Notas}

\footnotetext{
' DARNTON, 1990, p. 190.

${ }^{2}$ Lei que assegurava às mulheres o direto de sentarem, durante o trabalho, a fim de descansarem.

${ }^{3}$ GOMES, 2003.

${ }^{4}$ Joana Maria PEDRO, 2005.
} 


\section{Referências bibliográficas}

DARNTON, Robert. O beijo de Lamourrette. São Paulo: Cia. das Letras, 1990.

GOMES, Ângela de Castro. "Venturas e desventuras de uma república de cidadãos". In: ABREU, Martha; SOIHET, Rachel (Orgs.). Ensino de história: conceitos, temáticas e metodologia. Rio de Janeiro: Casa da Palavra, 2003. p. 152-167.
PEDRO, Joana Maria. "Traduzindo o debate: o uso da categoria gênero na pesquisa histórica". Revista História, São Paulo: Editora UNESP, v. 24, n. 1, p. 77-98, 2005.

Lorena Zomer Universidade Federal de Santa Catarina Mário Martins Viana Júnior Universidade Federal de Santa Catarina 